\title{
Cardiovascular and Self-Reported Recovery in Two-Shift Systems
}

\author{
A Cross-Sectional Study in German Shift Workers \\ of the Hotel and Catering Industry
}

\author{
Lisa Stieler ${ }^{1}$, Bettina Hunger ${ }^{2}$, and Reingard Seibt ${ }^{1}$ \\ ${ }^{1}$ Institute for Preventive Medicine, Rostock University Medical Center, University of Rostock, University Medicine Rostock, Germany \\ ${ }^{2}$ Government Safety Organization Foods and Restaurants, German Social Accident Insurance Institution for the Foodstuffs \\ and Catering Industry, Office of Coordination Potsdam, Germany
}

\begin{abstract}
Recovery is necessary to maintain workers' health and efficiency. Shift work has been associated with delayed recovery processes. The objective of this study was to examine the cardiovascular and self-reported recovery measures of German shift and day workers in the hotel and catering industry. Furthermore, it aimed to clarify to what extent shift groups differentiate given additional factors that influence recovery (ability to relax, lifestyle). The sample group consisted of 64 alternative shift workers (two-shift system with a low proportion of night work) and 96-day workers employed in the hotel and catering industry. Blood pressure monitoring was conducted for $24 \mathrm{hr}$ during a working day, including the phases of work, leisure, and sleep, to assess cardiovascular reduction during leisure and sleep. The blood pressure status was measured over the course of a 4-day self-assessment period. Self-reported measures, including quality of sleep (Pittsburgh Sleep Quality Index, PSQI), work-life balance (WPC), ability to relax (FABA), and lifestyle factors (physical activity, smoking, drinking), were assessed through questionnaires. Sixty-one participants (36\%) were hypertensives. There were no significant effects of cardiovascular recovery regarding the reduction of blood pressure for the calculated differences between WORK - LEISURE, WORK - SLEEP, and LEISURE - SLEEP among shift and day workers. Shift workers reported a significantly less favorable work-life balance $(p=.017)$, a decreased ability to relax $(p=.001)$, and less regular physical activity $(p=$.003). The workload within the two-shift system of the hotel and catering industry seems to have a lesser effect on cardiovascular means than on self-reported measures of recovery. The decisive factor is the ability to relax, which means psychological detachment from work. To enable a comprehensive recovery, an optimally designed recovery cycle is necessary for shift systems.
\end{abstract}

Keywords: recovery, shift work, 24-hour monitoring, sleep, work-life balance

Over the past few years, shift work has increased in industrialized countries, such as Germany (Eurofound, 2017). Shift work can be defined as a particular form of workload which occurs at different times of the day: workers regularly succeed one another at the same work station to extend daily operating times (Costa, 2016), or they constantly work at unusual times (e.g., frequent night shifts). Distinctions are made between regular day work and alternative shift systems, including morning, afternoon, and night shifts, so that shift workers often work and sleep at improper times of the day. Since the human organism struggles to adapt to these ever-changing circumstances of alternative shift systems, all physiological processes that usually depend on circadian rhythms and sleep (e.g., cortisol levels, blood pressure) are disrupted (Depner et al., 2014). Shift workers have to endure phase shifts every time they change work shifts, so their circadian rhythms need to resynchronize according to the changing workload. This can lead to high blood pressure (Vyas et al., 2012; Yeom et al., 2017) and delayed cardiovascular unwinding during the night (Hermida et al., 2013). Furthermore, shift workers often report suffering from different health problems (Costa, 2010, 2016; Lajoie et al., 2015; Vyas et al., 2012), disturbed sleep (Akerstedt, 2003; Lajoie et al., 2015), and bad sleep quality (Lajoie et al., 2015; McDowall et al., 2017; Merkus et al., 2015).

Shift work not only goes along with changes in circadian rhythms but also with psychosocial stress (Kecklund \& Axelsson, 2016). Irregular working and sleeping hours, that are inconsistent with those of the general population or family members, are associated with an unbalanced social life and insufficient work-life balance (WLB; Costa, 2010; Wiener, 2014).

Due to the high workload connected with shift work, proper recovery is necessary. Recovery can be determined using objective indicators (cardiovascular indicators, e.g., blood pressure - BP) and self-reported assessments (sleep, WLB). Based on the Allostasis Model (McEwen, 1998), 
cardiovascular indicators as BP increase during stress and decrease during recovery. Thus, the difference between stress and recovery phases can be viewed as an objective indicator of recovery.

Sleep and its quality are important indicators of recovery and influence it to a substantial degree (Demerouti et al., 2009). As WLB is important for recreational processes, it can be used as a self-reported measure of recovery: through sufficient recovery, enough resources should be made available to avoid a conflict between work and family (Zijlstra \& Sonnentag, 2006).

How shift work affects recovery depends on a variety of interacting mechanisms (Kecklund \& Axelsson, 2016), such as the ability to relax. This ability is seen as a generalized approach to occupational stress tolerated by employees, although it leads to restrictions during the recovery (Richter et al., 1996). How working a two-shift system (rotating morning and afternoon shifts) affects recovery has not yet been sufficiently examined. However, there have been associations between high workload (such as shift work) and a poor ability to relax (Rau, 2004).

The German hotel and catering industry (HCI) represents an industrial sector where $67 \%$ of the employees work in shifts (often with a low proportion of night work; Deutscher Hotel- und Gaststättenverband e.V., 2015; Eurofound, 2004). The employees are subjected to a high workload, and a high degree of flexibility is required (Lajoie et al., 2015; McDowall et al., 2017; Merkus et al., 2015). Therefore, mainly young people, especially women, work in the HCI (Eurofound, 2004).

The objective of this study is to find out if, compared to day workers, workers in two-shift systems with a low proportion of night work report a less favorable cardiovascular (unwinding in BP) and self-reported (sleep, WLB) recovery. Furthermore, we want to examine to what extent the two shift systems affect additional factors influencing recovery, such as the ability to relax and lifestyle factors (physical activity, smoking, drinking). According to previous studies, shift workers are expected to experience insufficient cardiovascular unwinding and to report a worse quality of sleep, an unfavorable WLB, and an unhealthier lifestyle.

\section{Methods}

\section{Participants}

For this ex post facto cross-sectional analysis, the data were collected within the scope of an occupational screening program. A total of 160 employees volunteered at 11 high-category hotels that are supervised by the Government Safety Organization Foods and Restaurants. Bulletins and
Table 1. Characteristics of sample

\begin{tabular}{|c|c|c|}
\hline & $\begin{array}{l}\text { Shift workers } \\
\qquad n=64\end{array}$ & $\begin{array}{c}\text { Day workers } \\
\quad n=96\end{array}$ \\
\hline Age [years], $M \pm S D$ & $32.3 \pm 9.0$ & $36.6 \pm 10.1$ \\
\hline \multicolumn{3}{|l|}{ Sex \% $(n)$} \\
\hline Men & $50(32)$ & $42(40)$ \\
\hline Women & $50(32)$ & $58(56)$ \\
\hline Working hours per week (hr) & $42.3 \pm 5.1$ & $41.8 \pm 8.8$ \\
\hline Hypertension \% (n) & $44(28)$ & $34(33)$ \\
\hline \multicolumn{3}{|l|}{ Education \% (n) } \\
\hline High school & $38(24)$ & $50(48)$ \\
\hline Middle school & $55(35)$ & $46(44)$ \\
\hline Secondary modern school & $8(5)$ & $3(3)$ \\
\hline
\end{tabular}

Note. $N=160 . N=$ sample; $\%(n)=$ frequency in \% (subsample); $M=$ mean $S D=$ standard deviation.

flyers distributed in the hotels attracted the attention of the participants.

The Ethics Committee of the Technical University Dresden (EK 250397) approved the study and written informed consent was obtained from all participants included in this study.

Characteristics of the study population are presented in Table 1. Shift workers (SW) alternated morning shifts (start: 6:00-9:00 a.m.; end: 3:00-7:00 p.m.) with afternoon shifts (start: 12:00-03:00 p.m.; end: 9:00 p.m.-12:00 a.m.), while day workers (DW) worked (relatively standard) day shifts (start: 6:00-9:00 a.m. end: 2:30-5:30 p.m.). According to the working times of the HCI, afternoon shifts have a low proportion of night work.

The occupations of the HCI employees were diverse, for example, cooks (19\%), hotel staff $(16 \%)$, administrative staff (33\%), room service/housekeeping staff (9\%), reception (13\%), and other service areas (including maintenance, home automation, security, customer care, sales, and marketing). In this context, it should be noted that $47 \%$ of SW and only $33 \%$ of DW performed physically demanding activities (e.g., housekeeping, service activities), while, conversely, only $17 \%$ of SW and $43 \%$ of DW performed predominantly mentally demanding activities (e.g., reception, administration).

Since 12 of the participating HCI employees were being treated with antihypertensive medication, they were excluded from the statistical BP analysis.

\section{Physiological Measure - Blood Pressure}

For the extended cardiovascular health screening, a BOSO medicus BP measuring device (Bosch + Sohn $\mathrm{GmbH}$, Jungingen, Germany) was used. The determination of the $\mathrm{BP}$ status was conducted in form of a BP self-measurement 
( $n=24)$ on 2 working days and 2 days off, between 6 a.m. and 10 p.m. Hypertensives were diagnosed when their systolic (SBP) and/or diastolic (DBP) BP mean value was $>$ 135/85 mmHg (Williams et al., 2018). Participants were given brief instructions in advance (including the start of measurement after a 3-minute rest (sitting down) and staying seated with their arm supported during measurement).

Twenty-four-hour monitoring was used to collect BP under working and recovery conditions (leisure, sleep). The monitor took readings every $15 \mathrm{~min}$ throughout the day, and every $30 \mathrm{~min}$ at night (10 p.m.-6 a.m.). The readings were allocated to the time periods WORK (time between beginning and end of work with recovery periods), LEISURE (time between end of work and going to bed, including sleep periods during the day), and SLEEP (time between going to bed and rising the next morning). Mean values and standard deviations were calculated for SBP and DBP for each phase. Parallelly, the participants wrote in an activity diary at an hourly interval to enable a clear assignment of the measured values within each time phase.

\section{Self-Reported Measures}

Sociodemographic (e.g., age, gender, school-leaving qualifications), occupational (e.g., shift system, length of employment), and general information about the health status (e.g., intake of antihypertensive drugs) were collected using a modified shift worker questionnaire (Barton et al., 1995, modified by Seibt \& Spitzer, 2011). Sleep behavior was determined by employing the Pittsburgh Sleep Quality Index (PSQI; Buysse et al., 1989). A low global score (021 points) corresponds to better sleep quality (good: 0-5 points; poor sleepers: 6-10 points; people with chronic sleep disorders: $>10$ points). WLB was assessed using the workprivacy conflict scale (WPC; Netemeyer et al., 1996). Whereby a lower score (5-25 points) means a less favorable WLB. As there are no standard or cut-off values, the percentile values (15th and 85th percentile according to the Work-Ability-Index (Tuomi et al., 1998) were used to divide the score into the categories unfavorable (5-10 points), normal (11-22 points), and favorable (23-25 points).

To determine the ability to relax, the study utilized the scale from the questionnaire for faulty attitudes and behavior analysis relevant to coping with work demands (FABA; Richter et al., 1996): the lower the total score (6-24 points), the better the ability to relax. Based on percentile values, the score can be evaluated as a normal $(<75 \%)$, conspicuous (75-90\%), and very conspicuous $(\geq 90 \%)$ ability to relax. Standard values are available for the age ranges of $<30$ years, $30-50$ years, and $>50$ years.

Lifestyle (physical activity, smoking, drinking) was also analyzed. Employees were asked whether they engaged in physical activities (not at all, occasionally, regularly), smoked (yes or no), and how often they consumed alcohol per week (not at all, occasionally, regularly).

\section{Statistical Analysis}

Statistical analyses were performed using the Statistical Package for the Social Sciences software. The expectation-maximization algorithm was applied to complete missing data. Analyses of covariance (ANCOVAs) were applied during the examination of differences in the recovery measures among the shift groups. Since covariates exerted significant influence on recovery and health, statistical adjustments to age and sex were made for all analyses. Additionally, adjustments to BP status were made only for the analysis of cardiovascular measurements. Age effects were examined according to the FABA (Richter et al., 1996). An error probability value of $p<.05$ was considered statistically significant and supplemented by effect sizes (Cohen, 1988).

\section{Results}

Analysis of BP self-measurements $(n=148)$ showed that $40 \%$ of SW and $33 \%$ of DW were hypertensives $(p=$ .380). A significant effect of sex and age on BP $(p<.001-$ .043) was confirmed, according to which men $(M \pm S D=$ $134 / 81 \pm 12 / 9 \mathrm{mmHg}$ ) had a higher mean BP than women $(M \pm S D=123 / 78 \pm 13 / 9 \mathrm{mmHg})$, and BP increased with age. These results support the selection of covariates (sex, age, BP status).

SW had significantly higher BP values than DW during WORK (SW: $M \pm S D=146 / 87 \pm 14 / 8 \mathrm{mmHg}$, DW: $M \pm$ $S D=140 / 84 \pm 15 / 10 \mathrm{mmHg} ; p=.034-.044$, small effects). During LEISURE (SW: $M \pm S D=139 / 82 \pm 12 / 8 \mathrm{mmHg}$, DW: $M \pm S D=136 / 81 \pm 14 / 8 \mathrm{mmHg}$ ) and SLEEP (SW: $M \pm S D=113 / 64 \pm 15 / 8 \mathrm{mmHg}$, DW: $M \pm S D=109 / 63 \pm$ $13 / 7 \mathrm{mmHg}$ ), there were no differences between the two shift groups $(p=.113-.443)$.

Figure 1 shows the cardiovascular reduction for SW and DW. Neither during the recovery phase LEISURE (difference WORK - LEISURE: W-L) nor SLEEP (difference WORK - SLEEP: W-S) were there any significant differences in BP $(p=.175-.250 ; p=.238-.536)$ between SW and DW (Figure 1).

Concerning the study population, the difference between $\mathrm{W}$-L was on average $5 \mathrm{mmHg}$ (SBP) and $4 \mathrm{mmHg}$ (DBP), while the average reduction for $\mathrm{W}-\mathrm{S}$ was $32 \mathrm{mmHg}(\mathrm{SBP})$ and $22 \mathrm{mmHg}$ (DBP). This corresponded, on average, to a nocturnal SBP unwinding of $21 \%$ for both SW and DW, or rather for DBP $25 \%$ (SW) and 24\% (DW), which is regarded as over dipping (Middeke, 2016). 


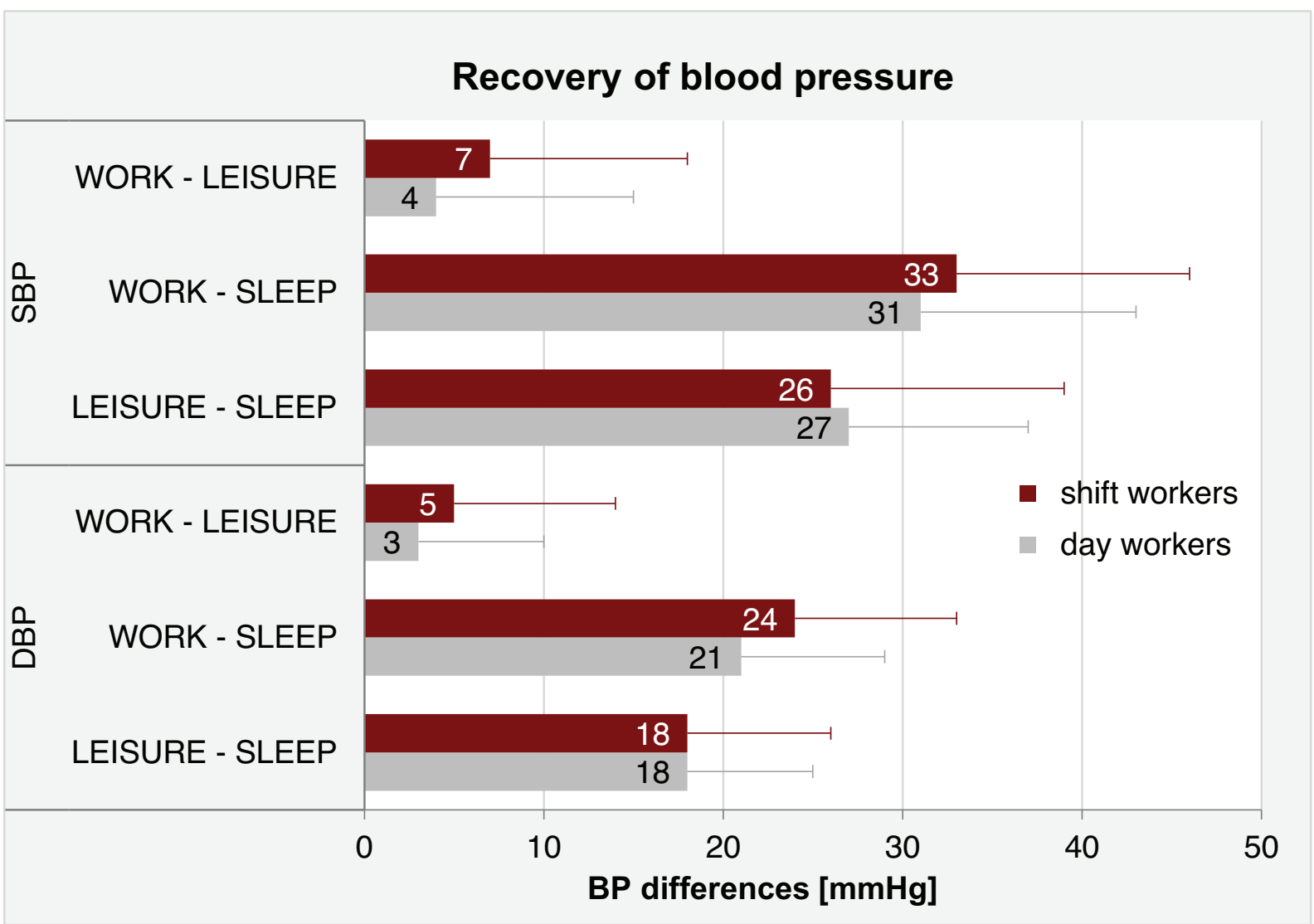

Figure 1. Absolute differences (WORK - LEISURE, WORK - SLEEP, LEISURE - SLEEP) of blood pressure (BP: SBP = systolic BP; DBP = diastolic BP) among shift $(n=60)$ and day worker $(n=88)$ (mean \pm standard deviation).

Sex (W-L: $p=.385-.977 ; \mathrm{W}-\mathrm{S}: p=.060-.470)$, age (W-L: $p=.275-.850 ; \mathrm{W}-\mathrm{S}: p=.421-.331$ ), and BP status (W-L: $p=$ .493-.751; W-S: $p=.418 .-.527$ ) had no impact on cardiovascular recovery during LEISURE and SLEEP.

Self-reported recovery measures are represented in Table 2. Regarding the analysis of sleep, no significant difference was found between SW and DW ( $p=.214$, Table 2). On average, SW slept $6.7 \mathrm{hr}$ and DW $6.6 \mathrm{hr}(p=.214)$. In the total sample, $59 \%$ of employees reported good quality of sleep and $34 \%$ poor quality of sleep. Six percent reported chronic insomnia. Sex $(p=.045)$ and age $(p=.040)$ had an influence on the quality of sleep. Men reported slightly better sleep quality $(M \pm S D=5.1 \pm 2.4$ points $)$ than women $(M \pm S D=6.0 \pm$ 3.2 points). The quality of sleep decreased with age: HIC employees younger than 30 years reported a good quality of sleep ( $M \pm S D=5.2 \pm 2.6$ points), while those over 50 years of age ( $M \pm S D=6.4 \pm 3.9$ points) had poorer quality of sleep.

On average, SW reported a significantly less favorable WLB than DW ( $p=.017$, Table 2). Fourteen percent of the total sample of employees rated their WLB as favorable, $67 \%$ as normal, and $19 \%$ as unfavorable. For sex $(p=.211)$ and age $(p=.758)$, no significant effects on the WLB were observed.
Of the total sample, $74 \%$ reported a "normal" ability to relax, $17 \%$ reported a conspicuous, and $9 \%$ a very conspicuous value. SW gave an average score of 16 points $(17 \%$ very conspicuous values) and DW of 14 points (3\% very conspicuous values, $p=.001$, Table 2). With increasing age, the ability to relax was less favorable $(p=.049)$ : The average score for participants under 30 years of age was 14 points, while the average score for participants aged 50 and older was 16 points. Sex had no influence on the ability to relax $(p=.313)$.

DW were significantly more likely to exercise regularly than SW (53\% vs. $30 \%, p=.003$; small effect). If one considers those who are regularly athletically active, both shift groups exercised $4 \mathrm{hr}$ per week on average. Between the two shift groups, no significant differences were found for smoking and drinking (smokers: SW 42\% vs. DW 37\%; regular alcohol consumption: SW 19\% vs. DW 16\%). However, sex differences were confirmed: $47 \%$ of men and $32 \%$ of women stated $(p=.047)$ that they were smokers. Men consumed alcohol significantly more often than women (regular alcohol consumption: men $38 \%$ vs. women $16 \%$; $p=.010)$. 
Table 2. Self-reported measures of shift and day workers

\begin{tabular}{|c|c|c|c|c|}
\hline & $\begin{array}{c}\text { Shift workers } \\
n=64\end{array}$ & $\begin{array}{c}\text { Day workers } \\
n=96\end{array}$ & Test statistics & $p$-value $\left(\eta_{p}^{2}\right)$ \\
\hline \multicolumn{5}{|l|}{ Self-reported measures } \\
\hline Sleep - PSQI-Score (points), $M \pm S D$ & $5.7 \pm 2.6$ & $5.4 \pm 3.1$ & 1.56 & $.214(.010)$ \\
\hline Sex & & & 4.07 & $.045^{\star}(.025)$ \\
\hline Age & & & 4.29 & $.040 *(.027)$ \\
\hline WLB - WPC-Score (points), $M \pm S D$ & $14.5 \pm 5.7$ & $16.8 \pm 5.5$ & 5.87 & $.017 *(.036)$ \\
\hline Sex & & & 1.58 & $.211(.010)$ \\
\hline Age & & & 0.10 & $.758(.001)$ \\
\hline Ability to relax - FABA-Score (points), $M \pm S D$ & $15.7 \pm 4.2$ & $13.9 \pm 3.8$ & 10.79 & $.001 * *(.065)$ \\
\hline Sex & & & 1.03 & $.313(.007)$ \\
\hline Age & & & 3.89 & $.049 *(.024)$ \\
\hline
\end{tabular}

Note. $N=160$. WLB = Work-life-balance; $M=$ mean; $S D=$ standard deviation. Test statistics: ANCOVA (F-value); Effect size: $\eta^{2}$. Significance threshold (twotailed): ${ }^{\star} p<.05 ;{ }^{* \star} p<.01 ;{ }^{* *} p<.001$.

\section{Discussion}

In summary, this study found that cardiovascular unwinding did not differ between SW and DW. As expected, however, a less favorable WLB, poorer ability to relax, and less regular physical activity were confirmed for SW. Contrary to the results of known studies (Lajoie et al., 2015; McDowall et al., 2017; Merkus et al., 2015), there were no differences in self-assessed sleep quality between the two shifts groups. It was not expected that this form of shift work would have so little effect on cardiovascular recovery but instead on self-reported recovery measures.

The strength of the study is that it analyzed cardiovascular blood pressure over the course of $24 \mathrm{hr}$ under real WORK conditions, during LEISURE, and SLEEP, in combination with self-reported recovery measures. Thus, the study provides important information on the range of physiological responses in a relatively young sample group and, at the same time, provides a starting point for preventive action in HCI.

This study has some limitations, such as the crosssectional design, which does not allow any interpretation of causal relationships. In addition, the generalizability of this study was limited by the convenience sampling of 160 employees and the fact that participation was voluntary. Thus, selection effects, such as the healthy worker effect (Shah, 2009), cannot be excluded. Moreover, the questionnaires that were used, are based on self-reports, which may be biased by the effects of social desirability. In addition, the low average age of the sample group and its relatively good state of health may conceal the proportion of variance caused by the shift system. Existing results mostly refer to shift systems with night work. Results for two-shift systems with a low proportion of night work during the late shift are missing. In future studies, a comparison between day work and alternative shifts including night work can provide more information. Moreover, additional physiological markers of cardiovascular function or stress (e.g., heart rate variability, cortisol levels) could add further value to future studies,

SW had higher blood pressure than DW during WORK. There were no differences between the two shift groups regarding LEISURE and SLEEP phases. This may be less credited to the shift work rather than to the work activity, as $47 \%$ of the SW and only $33 \%$ of the DW performed physically demanding activities.

Compared to WORK, the BP during LEISURE decreased by an average of only 3-7 mmHg (Figure 1). This suggests a high level of activity during LEISURE. The standard deviations of BP (SBP: $13 \mathrm{mmHg}$; DBP: $8 \mathrm{mmHg}$ ) show that very different and diverse active and passive activities (e.g., watching television, reading newspaper) were conducted. This means that high cardiovascular strain during LEISURE is not only an expression of insufficient recovery but can be a sign of physical activity (e.g., sports, walking, cycling). Physical activities, social activities, and hobbies are classified by the scientific literature as recreational factors (Demerouti et al., 2009) and can contribute to good health - even if BP increases during these activities. In order to draw conclusions about an actual cardiovascular recovery effect, the individual activity protocols must be included in the interpretation of the results.

Sleep quality of SW and DW was not assessed differently. However, men reported a better quality of sleep than women $(p=.045)$, and the quality of sleep decreased with rising age $(p=.040)$. Since this HCI study was performed on a very young sample ( $M=35$ years), it can be assumed that they can more accurately compensate for shift works' negative effects on sleep, rather than older employees. In addition, shift work without night work seems to have a less pronounced effect on sleep quality in this study. 
However, SW rated their WLB less favorably than DW $\left(\eta^{2}=.04 ;\right.$ small effect). This corresponds to previous study results, according to which shift work influences social life and can lead to a desynchronized social rhythm compared to people who do not work shifts (Costa, 2010; Wiener, 2014) Therefore, interference between work and private life can occur. The type of shift system and its direction of rotation are decisive for the WLB.

SW reported a significantly poorer ability to relax than DW $\left(\eta^{2}=.07\right.$, medium effect). Very conspicuous values were reported by $17 \%$ of SW and only $3 \%$ of DW. This highlights its importance for the recovery process. Then again, the results underline that the two-shift systems examined in the HCI do not yet sufficiently contribute to a balanced effort-recovery cycle. Shift systems should also be designed in a way that they enable "healthy" work and relaxation phases. The recovery effect during spare time depends not only on its duration but also on its quality. Detaching from work promotes recovery but worrying about work problems may impair it (Geurts \& Sonnentag, 2006). If there is no possibility of regeneration over a longer period of time, health consequences, such as high BP, are inevitable (Seibt et al., 1998). Hence, the ability to relax can also be viewed as an important indicator to assess workloads.

Regarding physical activities, $44 \%$ of the participants (men: 50\%, women: 39\%) stated that they regularly engage in sports and are thus, comparable to the average German population in the corresponding age range (Finger et al., 2017). However, more DW than SW (53\% vs. $30 \%, p=$ .003 , small effect) were regularly active. Smoking was not significantly different between SW (42\%) and DW (37\%), but $47 \%$ of men and $32 \%$ of women $(p=.047)$ stated that they were smokers. This is in line with the average German smoking rate in the according to age range (Zeiher et al., 2017).

Recovery processes have a significant influence on the health of employees (effort-recovery cycle). According to Bloom et al. (2009), recovery processes after work contribute decisively to maintain mental well-being and health.

Regarding the results of the present study, a two-shift system with a low proportion of night work does not necessarily correlate with the decreased cardiovascular recovery of the employees. The self-reported measures of recovery and lifestyle show that the balance between stress and recovery is, nevertheless, disturbed for some of the HCI employees.

Although cardiovascular recovery measures did not differ between the two shift systems, they are necessary to assess the cardiovascular risk of employees (Seibt et al., 2018). Overall, $36 \%$ of the sample presented with undiscovered hypertension. The occupational screening program, with self-measurement and 24-hour monitoring of BP, is a suitable approach for detecting workers at risk. However, in order to assess the actual recovery, other measures proved equally important in the current study, so that self-reported recovery deficit are best presented subjectively (WLB, ability to relax). To assess stress and the ability to recover, it is, therefore, necessary not only to study biological markers but also to combine them with self-reported indicators.

\section{Key Points}

- Cardiovascular unwinding of blood pressure during the night did not differ between alternating shift workers with a low proportion of night work and regular day workers.

- A less favorable WLB, a poorer ability to relax, and less regular physical activity were confirmed for shift workers. But there were no differences between the two shift groups in self-assessed sleep quality.

- The ability to relax is the decisive factor for recovery in this study. This ability can also be seen as an important indicator helping to assess workloads.

- An occupational screening program with self-measurement and 24-hour monitoring of blood pressure as well as the assessment of behavioral indicators (sleep, WLB, ability to relax) is a suitable approach for early detecting workers at risk.

\section{References}

Akerstedt, T. (2003). Shift work and disturbed sleep/wakefulness. Occupational Medicine, 53(2), 89-94. https://doi.org/10.1093/ occmed/kgg046

Barton, J., Spelten, E., Totterdell, P., Smith, L., Folkard, S., \& Costa, G. (1995). The standard shiftwork index: A battery of questionnaires for assessing shiftwork-related problems. Work \& Stress, 9(1), 4-30. https://doi.org/10.1080/02678379508251582

Bloom, J., Kompier, M., Geurts, S., Weerth, C., Taris, T., \& Sonnentag, S. (2009). Do we recover from vacation? Metaanalysis of vacation effects on health and well-being. Journal of Occupational Health, 51(1), 13-25. https://doi.org/10.1539/joh. K8004

Buysse, D. J., Reynolds, C. F., Monk, T. H., Berman, S. R., \& Kupfer, D. J. (1989). The Pittsburgh Sleep Quality Index: A new instrument for psychiatric practice and research. Psychiatry Research, 28(2), 193-213. https://doi.org/10.1016/0165-1781 (89) $90047-4$

Cohen, J. (1988). Statistical power analysis for the behavioral sciences. Erlbaum.

Costa, G. (2010). Shift work and health: Current problems and preventive actions. Safety and Health at Work, 1(2), 112-123. https://doi.org/10.5491/SHAW.2010.1.2.112

Costa, G. (2016). Introduction to problems of shift work. In I. IskraGolec, J. Barnes-Farrell, \& P. Bohle (Eds.), Social and family issues in shift work and non standard working hours (pp. 1935). Springer International Publishing. https://doi.org/10.1007/ 978-3-319-42286-2_2 
Demerouti, E., Bakker, A. B., Geurts, S. A. E., \& Taris, T. W. (2009). Daily recovery from work-related effort during non-work time. In S. Sonnentag, P. L. Perrewé, \& D. C. Ganster (Eds.), Research in occupational stress and well-being (Vol. 7, pp. 85-123). Emerald Group Publishing. https://doi.org/10.1108/S14793555(2009)0000007006

Depner, C. M., Stothard, E. R., \& Wright, K. P. (2014). Metabolic consequences of sleep and circadian disorders. Current Diabetes Reports, 14(7), Article 507. https://doi.org/10.1007/ s11892-014-0507-z

Deutscher Hotel- und Gaststättenverband e.V. (2015). Wirtschaftskraft und Jobmotor: Zahlen, Daten, Fakten 2015 [Economic strength and job generator: Numbers, dates, facts 2015]. Berlin.

Eurofound. (2004). EU hotel and restaurant sector: Work and employment conditions. Office for Official Publications of the European Communities.

Eurofound. (2017). 6th European working conditions survey: Overview report. 2017 update. Publications Office of the European Union.

Finger, J. D., Mensink, G. B. M., Lange, C., \& Manz, K. (2017). Gesundheitsfördernde körperliche Aktivität in der Freizeit bei Erwachsenen in Deutschland [Health-promoting physical activity during leisure time among adults in Germany]. Journal of Health Monitoring, 2(2), 37-44. https://doi.org/10.17886/RKIGBE-2017-027

Geurts, S. A., \& Sonnentag, S. (2006). Recovery as an explanatory mechanism in the relation between acute stress reactions and chronic health impairment. Scandinavian Journal of Work, Environment \& Health, 32, 482-492. https://doi.org/10.5271/ sjweh.1053

Hermida, R. C., Ayala, D. E., Mojón, A., \& Fernández, J. R. (2013). Blunted sleep-time relative blood pressure decline increases cardiovascular risk independent of blood pressure level-The "normotensive non-dipper" paradox. Chronobiology International, 30(1-2), 87-98. https://doi.org/10.3109/07420528. 2012.701127

Kecklund, G., \& Axelsson, J. (2016). Health consequences of shift work and insufficient sleep. British Medical Journal, Article i5210. https://doi.org/10.1136/bmj.i5210

Lajoie, P., Aronson, K. J., Day, A., \& Tranmer, J. (2015). A crosssectional study of shift work, sleep quality and cardiometabolic risk in female hospital employees. British Medical Journal Open, 5(3), Article e007327. https://doi.org/10.1136/bmjopen2014-007327

McDowall, K., Murphy, E., \& Anderson, K. (2017). The impact of shift work on sleep quality among nurses. Occupational Medicine, 67(8), 621-625. https://doi.org/10.1093/occmed/kqx152

McEwen, B. S. (1998). Stress, adaptation, and disease: Allostasis and allostatic load. Annals of the New York Academy of Sciences, 840, 33-44.

Merkus, S. L., Holte, K. A., Huysmans, M. A., van de Ven, P. M., van Mechelen, W., \& van der Beek, A. J. (2015). Self-reported recovery from 2-week 12-hour shift work schedules: A 14-day follow-up. Safety and Health at Work, 6(3), 240-248. https:// doi.org/10.1016/j.shaw.2015.07.003

Middeke, M. (2016). Nächtlicher Blutdruckabfall: Von ,,normal dippern“ bis ,,reverse dippern“ - Wer ist gefährdet? [Nocturnal blood pressure decline: From normal to reverse dippers - Who is at the highest risk?] Deutsche Medizinische Wochenschrift, 141(12), 847-847. https://doi.org/10.1055/s-0042-106989

Netemeyer, R. G., Boles, J. S., \& McMurrian, R. (1996). Development and validation of work-family conflict and family-work conflict scales. Journal of Applied Psychology, 81(4), 400-410. https://doi.org/10.1037/0021-9010.81.4.400

Rau, R. (2004). Job strain or healthy work: A question of task design. Journal of Occupational Health Psychology, 9(4), 322338. https://doi.org/10.1037/1076-8998.9.4.322
Richter, P., Rudolf, M., \& Schmidt, C. F. (1996). Fragebogen zur Analyse belastungsrelevanter Anforderungsbewältigung/FABA [Questionnaire for Faulty Attitudes and Behaviour Analysis relevant to coping with work demands]. Swets \& Zeitlinger, Swets Test Services.

Seibt, R., Boucsein, W., \& Scheuch, K. (1998). Effects of different stress settings on cardiovascular parameters and their relationship to daily life blood pressure in normotensives, borderline hypertensives and hypertensives. Ergonomics, 41(5), 634648. https://doi.org/10.1080/001401398186801

Seibt, R., Hunger, B., Stieler, L., Stoll, R., \& Kreuzfeld, S. (2018). Early detection of undiagnosed hypertension based on occupational screening in the hotel and restaurant industry. BioMed Research International, 1-9. https://doi.org/10.1155/2018/6820160

Seibt, R., \& Spitzer, S. (2011). Shift Work Questionnaire for employees of the hotel and catering industry (unpublished). Technische Universität Dresden.

Shah, D. (2009). Healthy worker effect phenomenon. Indian Journal of Occupational and Environmental Medicine, 13(2), 77-79. https://doi.org/10.4103/0019-5278.55123

Tuomi, K., Ilmarinen, J., Jahkola, A., Katajarinne, L., \& Tulkki, A. (1998). Work Ability Index (2nd ed.). Finnish Institute of Occupational Health.

Vyas, M. V., Garg, A. X., lansavichus, A. V., Costella, J., Donner, A., Laugsand, L. E., Janszky, I., Mrkobrada, M., Parraga, G., \& Hackam, D. G. (2012). Shift work and vascular events: Systematic review and meta-analysis. British Medical Journal, 345, Article e4800. https://doi.org/10.1136/bmj.e4800

Wiener, B. (2014). Schichtarbeit und Work-Life-Balance - Geht das? [Shift work and work-life balance - Is that possible?] In S. Böttcher, J. Csongàr, U. Schlegel, \& B. Wiener (Eds.), Schichtwechsel (pp. 19-42). Universitätsverlag Halle-Wittenberg.

Williams, B., Mancia, G., Spiering, W., Agabiti Rosei, E., Azizi, M., Burnier, M., Clement, D. L., Coca, A., de Simone, G., Dominiczak, A., Kahan, T., Mahfoud, F., Redon, J., Ruilope, L., Zanchetti, A., Kerins, M., Kjeldsen, S. E., Kreutz, R., Laurent, S., ... Desormais, I. (2018). 2018 ESC/ESH guidelines for the management of arterial hypertension: The task force for the management of arterial hypertension of the European Society of Cardiology and the European Society of Hypertension. Journal of Hypertension, 36(10), 19532041. https://doi.org/10.1097/HJH.0000000000001940

Yeom, J. H., Sim, C. S., Lee, J., Yun, S. H., Park, S. J., Yoo, C.-I., \& Sung, J. H. (2017). Effect of shift work on hypertension: Cross sectional study. Annals of Occupational and Environmental Medicine, 29(1), Article 11. https://doi.org/10.1186/s40557-017-0166-z

Zeiher, J., Kuntz, B., \& Lange, C. (2017). Rauchen bei Erwachsenen in Deutschland [Prevalence of smoking in the adult population of Germany. Results of the German Health Interview and Examination Survey for Adults (DEGS1)]. Journal of Health Monitoring, 2(2), 59-65. https://doi.org/10.17886/RKI-GBE2017-030

Zijlstra, F. R. H., \& Sonnentag, S. (2006). After work is done: Psychological perspectives on recovery from work. European Journal of Work and Organizational Psychology, 15(2), 129-138. https://doi.org/10.1080/13594320500513855

\section{History}

Received February 9, 2021

Revision received May 4, 2021

Accepted May 14, 2021

Published online September 23, 2021

\section{Acknowledgments}

This work was supported by the Government Safety Organization Foods and Restaurants in Mannheim, Germany. 


\section{Conflict of Interest}

All authors declare no actual or potential conflicts of interest, including any financial, personal, or other relationships with people or organizations that could inappropriately influence (bias) their work.

\section{Publication Ethics}

This study was conducted in conformance with the guidelines of the World Medical Association (WMA) Declaration of Helsinki and the ethical principles of medical research involving human subjects, amended by the 9th WMA General Assembly, Seoul, Republic of Korea, October 2008. The Ethics Committee of the Technical University Dresden (EK 250397) approved the study and written informed consent was obtained from all participants included in this study.

\section{Open Data}

The dataset supporting the conclusions of this article is not included or available, on the basis of agreed data protection commitments made to the participants.

\section{Funding}

Open access publication enabled by University of Rostock.

\section{Lisa Stieler}

Institute for Preventive Medicine

Rostock University Medical Center

University of Rostock, University Medicine Rostock

St.-Georg-Str. 108

18055 Rostock

Germany

lisa.stieler@gmx.net 